\title{
Feelings, Imagination and Self-Understanding
}

\author{
Maria Virgínia Machado Dazzani • \\ Waldomiro José Silva Filho
}

(C) Springer Science+Business Media, LLC 2010

\begin{abstract}
Starting from some considerations about the text 'Feelings in Literature' by Johansen (2010), this article discusses the topic of emotions from the standpoint of moral psychology, namely the relationship between emotions and the conduct of our moral life. From this assumption, we will argue that literature, as an exercise of imagination, helps us understand and evaluate our own emotions, what is essential for establishing our uniqueness, distinguishing ourselves from others. In literature we can learn about emotions and we can understand our own feelings. Literature plays an important role in cultural experience, triggering emotional responses.
\end{abstract}

Keywords Emotions $\cdot$ Feelings $\cdot$ Imagination $\cdot$ Literature $\cdot$ Moral life $\cdot$

Self-understanding

The word 'feeling' covers a wide variety of phenomena, ranging from basic physical sensations, like 'touch' or 'pain' to complex emotions like 'fear,' 'hate,' 'sadness,' 'anger,' 'happiness' or 'envy,' ‘jealousy,' 'pride' or 'resentment.' In Psychology (Vandenbos 2007) and Philosophy (Solomon 2004), this notion is frequently used to comprehend conscious and subjective experience of emotions. According to Valsiner (2007, p. 308), '[t]he subjective world of feelings (...) on the basis of which different circumscribed emotions (...) are differentiated through semiotically-based reflexivity. Such reflexivity entails a generalization based on recurrent unique experiences that lead to the establishment of the use of one concrete term.' The example he uses is that someone can say "I feel something" for what "fear" is what s/he feels. In this sense, 'feelings cannot be reduced to emotions'. Even recognizing the complex network of themes involved in the notion of "feeling", and the boundaries between

M. V. Machado Dazzani • W. J. Silva Filho $(\bowtie)$ Universidade Federal da Bahia, Salvador, Brazil e-mail: waldomiro.silva@pq.cnpq.br

M. V. Machado Dazzani

e-mail: dazzani@ufba.br 
feelings and emotions, for the intent of this comment we will often use both terms interchangeably.

Despite the emotions have an important place in our mental and social life, there is little agreement on this matter: from Plato and Aristotle to contemporary neuroscience there is a proliferation of dissenting views about the emotions and their role in our understanding of human nature (De Sousa 2010, p 43). However, some topics are recurrent: emotions are almost always considered ambiguous phenomena that involve bodily and mental manifestations which may have a broad spectrum of variations (e.g. intensity, valence, type and range of intentional objects etc.). Sometimes the emotions are seen as antagonists of rationality, despite the fact that they have an indispensable role in determining the quality of life and have influence over our actions; emotions help to define our goals and personal and social expectations (Marks 1986; Gibbard 1990, pp. 126-150; Blackburn 1998, pp. 8-21).

While Stecker (1984, p. 409) states that there is not a common view on the nature and meaning of emotions that is widely accepted in contemporary philosophy, Marks (1986, p. 3), by contrast, says that the contemporary analysis of emotions is dominated by a cognitive perspective. In fact, a predominant aspect in today's discussions, as noted by De Sousa (1987, p. xvi), is that emotions 'are often thought the most biological, the most somatic of our mental functions.' As 'contemporary neurocognitivist feeling theories,' in assimilating emotions directly to basic brain processes they have stimulated a vigorous growth of research to explain the physiology and chemistry of emotions and their role in the evolutionary process and in everyday life. Projects such as Damasio's (1994, 1999) have represented a hegemonic research program: the emotions would be related to the brain function of controlling and monitoring the tensions between the individual's body and the natural and social environment. Damasio (1994) showed that an individual injured in the prefrontal cortices of the brain lost the ability to experience certain emotions, and consequently had his ability to perform various actions severely impaired, affecting his social interactions.

However, besides a purely biological function, 'feelings' and 'emotions' instigates some issues in psychological and philosophical investigations about the moral life (Solomon 1984; De Sousa 1987; Gibbard 1990; Nussbaum 2001). In the history of ethics and moral theories, some emotions, e. g. 'pride,' 'shame,' 'resentment' and especially 'guilt' are at the heart of concepts of moral norms and values. Often both the vices (envy, jealousy, anger) and the virtues (compassion, benevolence, sympathy) are part of a vocabulary which has both emotional and moral connotations. Even in the occidental rationalist tradition the emotions have been constantly conceived as a dangerous threat to the morality and conduct of public life, many philosophers think about the emotions and passions as the center of the constitution of the individuality of an individual and hence the formation of her autonomy. One of the most important examples is found in the Nicomachean Ethics of Aristotle: for him, moral education is essentially an education of the emotions (Aristotle 1995, II.2 X.9). In this sense, from the tension between emotion and reason, the discourse about the emotions emerges from issues that concern the moral education of the person, self-control and self-realization.

In 'Feelings in Literature' Johansen (2010) presents a promising argument about both a semiotic treatment of feelings as to how emotions are important to the 
literature. His semiotic perspective suggests a shift from a strictly scientificbiological focus on the problem of emotions to an inquiry into the meaning of emotions: what role do they have in the way we understand our lives? Allow us to highlight three topics present in the article by Johansen:

a) different from music, literature works with the ability to create fictional worlds that in many aspects are similar to the world in which we currently find ourselves, in addition, one of the common reasons of our interest in storytelling is our empathy with characters that we generally imagine as if they were 'other people' like us;

b) an example of the presence of feelings in literary imagination are the poetic texts;

c) finally, in reference to the work of Dissanayake (2000, 2001), he addresses the idea that the beginning of the communicative relationship between a mother and her baby rests on certain devices characteristically poetic (in the sense of ' $a$ ' and 'b' above).

Even if we consider that the points ' $b$ ' and 'c' offer a broad and interesting subject - with consequences for research in psychology and education-we will deal with only the first point. What interests us here is not to discuss the problem from the standpoint of biological theories and aesthetics, but from the standpoint of moral psychology, namely how feelings and emotions play an important role in our understanding of ourselves and how the literature (and their fictional worlds) can be a means to this self-understanding. At this point, as highlighted by Nussbaum (2001), it is interesting to explore the work of the imagination in understanding of emotions and moral education. For her, the exemplary case of the work of imagination about feelings is art, especially music and literature.

With regard specifically to how we will address the relationship between literature and feelings, we point out first that, from our point of view, the literature requires two specific skills: imagination and linguistic ability to understand meanings and content attributions (mental). The main point of this paper is the fact that, for the individual, to understand her emotions (and not just feel them) is a key factor in her self-constitution and for her autonomy.

First, however, it would be important to clarify in what sense we understand the relationship between emotions and moral life.

\section{Emotions and Moral Life}

Firstly, we consider that the difference between a strictly biological and neurophysiological approach to emotions and a moral approach (or moral psychology) is not an ontological difference, but an explanatory one. For purposes of these observations, we believe that accepting a moral explanation in psychology should involve a psychological vocabulary or a vocabulary intentionally non-physical: a psychological explanation of a vocabulary is a psychological explanation of the 'intentions,' 'reasons,' 'will' and 'deliberation.' For Nussbaum (2001), if emotions are also intertwined with the cognitive faculties, like the discernment and action, if they also contain notions of value and relevance to life (especially for the 'good life'), then 
they cannot be separated from moral judgments. For instance, when someone states that $\mathrm{s} /$ he loves or hates, that $\mathrm{s} / \mathrm{he}$ has compassion or resentment of another person, these feelings express values, judgements and evaluations about the loved or hated person, about the reasons for empathy or antipathy. For us, emotions should be shown in this perspective, as a psychological and moral problem- that obviously does not deny the importance of biological explanations of emotions.

Therefore, if we consider the context of moral issues, emotional states cannot be seen as 'simply perceptions of arousals and bodily changes, as, for instance, feeling sick may be thought to be' (Blackburn 1998, p. 130). If emotions were only internal feelings, their role in our moral life would not be intelligible: shame is not equal to a 'pain' and the feeling of resentment is not the same as an 'itch'. Emotions are not feelings that we just realize to be feeling and their effects not end with body awareness. For Solomon (1984, p. 185) an emotion operates as a judgment of ourselves and our place in the world, a projection, in our bodies, of values and ideals, structures and mythologies. Emotions provide, as other forms of perception, a certain kind of consciousness about the world: 'our emotions tell us that some aspect of our relation to the world is well or ill.' (Currie and Ravenscroft 2002, p. 193). According to Nussbaum (2001, p. 19), emotion 'involves judgments about important things, in judgments which, in appraising the salient external object for our own well-being, we acknowledge our own neediness and incompleteness before parts of the world that we not fully control.' This does not mean that emotions are the only or decisive aspect of moral life. The view that morality is rooted in the emotions is commonly called emotivism (De Sousa 1987, pp. 304-305; Artosi 2000, pp. 358-363). Nussbaum (2001, p. 2) writes: 'To say that emotions prominent should form part of the subject matter of moral philosophy is not to say moral philosophy that should give emotions the privileged place of trust, or the regard them immune from rational criticism: They may be is no more reliable than any other entrenched set of beliefs.'

Furthermore, emotions and feelings are learned, as well as language (as suggested in Johansen 2010), and have a structure essentially dramatic, as suggested by De Sousa (1987, pp. 181-184), the names of emotions do not refer only to simple body experience within the individual, instead of that they receive their meanings, reactions, expectations, customs and values. Some emotions have a central role in our social life, in how we engage with the norms and law, as we form our moral judgments, and especially how we respond to the question: 'how to conduct our lives?' (Gibbard 1990, pp. 126-127). In Christian tradition, it is the case of 'resentment' and 'guilt' that are the basis of judgments in relation to standards, to our own actions and the actions of others.

For De Sousa (1987), we become familiar with the vocabulary of emotions in association with what he calls paradigmatic scenarios to which we are exposed from an early age and that are reinforced by religious discourse, culture and myths. Paradigmatic scenarios involve two aspects: a) an exemplary situation-type offering the characteristic objects of a specific emotion-type (e.g. romantic love and maternal love, indignation at injustice, hatred vengeance, compassion towards the weak etc.) and b) a characteristic set of responses or normal responses to situations. 
This relationship between the subjects' experience and culture is one of the fundamental precepts of cultural psychology (Valsiner 2000, 2007, Valsiner and Rosa 2007; Valsiner and Van Der Veer 2000). In this sense, in an interesting study in cultural psychology of emotions, Choi et al. (2007, p. 318), state that '[e]motions are culturally constructed. Culture tells people what they should feel and experience and how to express it in given situation'. Due to the diversity of cultures, it is not possible to establish an universal and transcultural model about feelings. However, some anthropological studies recognize the importance of feelings and emotions as key social and cultural facts (e.g. Davies and Spencer 2010, Lutz 1988; Rosaldo 1980). An understanding of cultures requires an understanding of how people experience feelings and how they communicate emotions to each other in their relationships (Choi et al. 2007).

\section{Imagination and Emotion}

Then, there would be a close relationship between education of the emotions and moral education. Nussbaum $(1990,2001)$ in her studies of Greek classical culture, emphasizes that imagination, especially in arts, has an important role both in understanding and in educating emotions, this would be the case, for example, of education of children and preparation for confrontation with moral crises (Nussbaum 2001, pp. 174-237). For her, one of the tasks of art is precisely to 'cultivate' the emotions.

Imagination enables us to project ourselves in other situation and observe, reflect and feel the world from another perspective than the current perspective. This other situation is not our current situation, now, but we can occupy a position in this other situation through imagination (Currie and Ravenscroft 2002). The perspective imaginatively assumed can even be a perspective of another person and not our perspective. Moreover it may occur that this other perspective involves beliefs that are really not our current beliefs. In fiction, especially in literature, we are often asked to imagine the experience of the character as if it were a real person. It is good to have clear, however, that an important requirement for the imagination is that we know that difference between the current situation and the imagined situation, because otherwise it would be simply a delusion, a hallucination, an alienation of the modern world. In addition, the imagination cannot be confused with a kind of introspection or with a trip to our inner worlds. Imagination allows the individual to devise situations in which, in one way or another, their beliefs, desires and thoughts, appear and interact in a context that is not the current context. This does not mean that the beliefs, desires and thoughts of this individual do not have the same force they have in the current context. Rather, this is often an occasion to confront and evaluate our beliefs, desires and thoughts.

Borrowing from Peircean semiotics, the text (literary or fictional) is itself a sign (representamen) evoking other signs (semiotic objects) from the reader's experience, Thus engendering intertextual interrelations that serves to construct an imaginary world of signs (interpretants). This signs in turn become originary signs to be (re) interpreted, in a dialogical perspective (Merrell 1997, 2002). Literature is a fertile 
ground for imagination and thought. In this sense, it is a dialogue between the self of a moment and the oncoming of the next moment. The self, then, is a fabricator which interacts dialogically with itself and others. Peirce uses the word 'sign' in the widest possible sense, as a medium for extending the interconnected fabric of signification. As such, the sign is determined by its object, and determines its interpretant. But in order that the fabric be extended, the sign must have already been embodied in a subject (which implies its own object). This being the case, the fabric remains independent of the sign; yet the sign, through its object, represents the fabric in the way that the latter represents itself to be. Literature as semiosis involves a constant shift back to other signs, and the pushing forward of signs toward new signs, in a never-ending process (Merrell 2003). This process favors the notion of the literary sign and linguistic signs of everyday cultural practices, and all modes of extralinguistic communication.

Literature (alongside other fictional forms that convey propositional content), is an example of the role that imagination plays in our lives. De Sousa (1987, p. 182) argues that paradigmatic scenarios, responsible for exposing us to the vocabulary of emotions, in certain cultures, are reviewed, examined and refined by literature. For what concerns us here, the theory of the emotions of Nussbaum (1990, 2001), for example, exploits the fact that the psychological and moral significance of emotions can be expressed and understood in a special way through art, especially literature (Johansen 2010). Literature - at least a certain type of literature-requires, in its own fulfillment as work of art that the people get involved with the narrative not only cognitively, but especially emotionally.

Johansen (2010) suggests that there is something specific in how literature deals with emotions. And that it would be connected directly to the role that language plays in literature. In fact, several authors, among psychologists and philosophers recognize a crucial difference between the imaginative experience of emotions in music and literature, and that the latter is characterized by linguistic expression and, consequently, for conveying propositional content, that is, the expressive literary event depends on communication through phrases that must not only be meaningful, but to express ideas, thoughts, beliefs, finally, have psychological content. Music is characteristically a non-propositional art. Experiencing a literary object requires that the reader understands the propositions expressed by the writer.

According to Johnson-Laird and Oatley (2008, p. 103) - if we cannot understand the propositional content of the sentence 'It is a truth universally acknowledged, that a single man in possession of a good fortune, must be in want of a wife' we cannot, likewise, understand the chain of feelings explored in the novel by Jane Austen, Pride and Prejudice. The propositional content of the novel and the plot that Austen uses to express this content lead us to experience a sequence of emotions, although we know that the characters and their actions in this novel are fictitious.

Johansen (2010) writes:

... literature has, because of language, the capacity to create fictional worlds that in many respects are similar to and related to the life world within which we live. One of the most important reasons for our emotional engagement in literature is our empathy with others and our constant imagining and hypothesizing on possible developments in our interactions with them. Hence, we understand and engage ourselves in fictional worlds. 
Literature can help us understand the relationship between propositional contents (contents that can be transmitted through language) and a wide spectrum of feelings, allowing us to imagine the causes, consequences, structure, ideas and responses to anomalous certain particular emotions. For this reason, literary fiction has a peculiar psychological effect because, unlike what usually happens in our daily lives, it can take a look at the same time detached and engaged over emotions from a wide range of circumstances (Johnson-Laird and Oatley 2008, p. 111).

Coming across the question 'how propositional contents in literature can arouse emotions in the reader?' Johnson-Laird and Oatley (2008, pp. 108-109) suggest three answers: a) literature deals with our emotional capacity for empathy because we identify with the characters in the narrative (almost always, but this is not a rule, we identify with the protagonists and resist to the antagonists), b) literature causes us some excitement about the characters, c) the events that unfold in narrative can be related to our personal memories and affections. The imaginative simulations in literary events and memories of personal life of the reader may emerge with emotional force allowing the reader to re-consider her own emotions (Oatley 1999).

The vocabulary of emotions is, as we said earlier, very large and very difficult to agree on a definition of an accurate picture. Oatley (1994) proposed a taxonomy of emotions of literary response. Moran (1994, p. 81) notes, however, that '[t]he sentiments that are tapped by words of art are various not only in the thoughts and feelings associated with them, but in their sources in the person, in their kinds of directedness, and in their relation to the thing that most immediately elicits them.'

According to Moran (1994, p. 79), real world and fictional world are really different and make a difference when emotional responses are triggered (e.g., during the narration of the suffering of a character or at a hospital bed where a friend is suffering). Meanwhile, Moran (1994, p. 106) writes that 'The realm of our emotional responses provides one of the clearer cases in which imagination is not so much to peering into some other world, as a way of relating to this one. Now it is clear that there is much controversy about the imagination and its relation to our cognitive and emotional states and how, through acts of imagination, we can have access to the world around us, the minds of others and ours. But it is undeniable that, somehow, what we think about the world, others and also about ourselves is, first imagined, narrated, learned and told. This makes us believe that our relationships and our commitments to imagined worlds are not closed within themselves, around the inner circle of a movie theater or on the chair where we read a novel, but rather what interests us in the imagined worlds is the same that interests us in the real world. This is why, for example, from the point of view of emotions in imaginative contexts, we can speak of something as 'imaginative resistance'. The reader may well reserve the right to make their own decisions about what is important or unimportant in the text precisely because he/she can adopt the same attitude towards the characters and events in the real world. It is common that a reader might think that what morally applies to the real world also applies to any possible world, including the world of fiction (Moran 1994, p. 100). The discussion between Moran (1994) and Walton (1990) reopened a path initiated by Hume in his 'On the Standard of Taste' on the limits of the imaginative act which became known as the problem of 
'imaginative resistance' (Walton 2006; Gendler 2000, 2006; Kieran and Lopes 2003; Weinberg and Meskin 2006).

Literary worlds operate in the same way as in imagined worlds in general, for example in the case of the philosophy, of the 'thought experiments', 'modal judgment' and 'counterfactual reasoning.' The common feature of these worlds created by the imagination is that they involve 'propositional imagination'- the philosophy, writes Nichols (2006, p. 1), would be 'unrecognizable if we extracted all the parts that depend on the imagination.' Likewise, 'everyday life would be unrecognizable if we excised imaginative activities.'

Films and novels, and other artistic expressions, describe or present unreal events that can trigger real emotions. According to Gerrig (1993, pp. 1-24 and 196-242) the strategies and cognitive and emotional mechanisms we use to understand fictional events are the same we use to understand the everyday world. Therefore, we can be happy or sad or angry about what they know to be just imaginary.

What are fictional are the narrated events, not the emotions that readers experience. The emotional aspects of imagination, for example, to imagine something with sadness, apprehension, or excitement, should be considered as part of how we imagine, how the reader relates himself to the work, and not as something that should belong to the content of what is imagined. Thus Moran opposes to think of fictional imagination in terms of 'fictional true'. Moran (1994, p. 93) writes: 'Only the content of what is imagined is fictional in any sense. The way in which it is imagined, on the other hand, is an aspect of the activity of imagining that one is really engaged in the fact-about one's real life and psychological attitudes.'

Finally, imagination allows us to have an essential experience in establishing our uniqueness, distinguishing ourselves from others (Bruner 2002). Our suggestion is that emotions play a constitutive role in the subjectivity and are learned, grown, reviewed. Imagination in literature, in turn, serves to put us in touch with feelings allowing us to understand how our emotion are expressed and communicated: through imagination we are introduced to the symbols that express emotions and, in the same way, we can understand ideal situations, ideal response, its consequences, its place in the broad spectrum of human feelings. In the end, we can learn about emotions and we can understand our own feelings.

\section{References}

Aristotle (1995). Nicomachean Ethics - The Complete Works of Aristotle (The Revised Oxford Translation), vol. 2, edited by Jonathan Barnes. Princeton: Princeton University Press, pp. 1.729_ 1.867 .

Artosi, A. (2000). The limits of emotivism. Ratio Juris, 13(4), 358-363.

Blackburn, S. (1998). Ruling passions: A theory of practical reasoning. Oxford: Oxford University Press. Bruner, J. (2002). Making stories: Law, literature, life. Cambridge: Harvard University Press.

Choi, S.-C., Han, G., \& Kim, C.-W. (2007). Analysis of cultural emotions: Undesrtanding of indigenous psychology for universal implications. In J. Valsiner \& A. Rosa (Eds.), The Cambridge handbook of sociocultural psychology (pp. 318-342). Cambridge: Cambridge University Press. 
Currie, G., \& Ravenscroft, I. (2002). Recreative mind: Imagination in philosophy and psychology. Oxford: Clarendon.

Damasio, A. (1994). Descartes' error: Emotion, reason, and human brain. New York: G. P. Putnam's Sons.

Damasio, A. (1999). The feeling of what happens: Body and emotion in the making of consciousness. New York: Harcourt Brace and Co.

Davies, J., \& Spencer, D. (Eds.). (2010). Emotions in the field: The psychology and anthropology of fieldwork experience. Stanford: Stanford University Press.

De Sousa, R. (1987). The rationality of emotions. Cambridge: MIT.

De Sousa, R. (2010). Emotion. Stanford Encyclopedia of Philosophy. http://plato.stanford.edu/archives/ spr2010/entries/emotion from the Spring 2010 Edition (04/10/2010).

Dissanayake, E. (2000). Art and intimacy: How the arts began. Seattle: University of Washington Press.

Dissanayake, E. (2001). Aesthetic incunabula. Philosophy and Literature, 25, 335-346.

Gendler, T. S. (2000). The puzzle of imaginative resistance. Journal of Philosophy, 97(2), 55-81.

Gendler, T. S. (2006). Imaginative resistance revisited. In S. Nichols (Ed.), The architecture of the imagination: New essays on pretence, possibility, and fiction (pp. 149-173). Oxford: Clarendon.

Gerrig, R. J. (1993). Experiencing narrative worlds: On the psychological activities of reading. New Haven: Yale University Press.

Gibbard, A. (1990). Wise choices, apt feelings: A theory of normative judgment. Cambridge: Harvard University Press.

Johansen, J. D. (2010) Feelings in literature. Integrative Psychological ad Behavioral Science. [doi:10.1007/ s12124-009-9112-0]

Johnson-Laird, P. N., \& Oatley, K. (2008). Emotions, music, and literature. In M. Lewis, J. Haviland-Jones, \& L. F. Barrett (Eds.), Handbook of emotions (pp. 102-113). New York: The Guilford.

Kieran, M., \& Lopes, D. M. (Eds.). (2003). Imagination, philosophy, and the arts. London: Routledge.

Lutz, C. (1988). Unnatural emotions. Chicago: University of Chicago Press.

Marks, J. (Ed.). (1986). The ways of desire. Chicago: Precedent.

Merrell, F. (1997). Peirce, signs, and meaning. Toronto: University of Toronto Press.

Merrell, F. (2002). Learning living living learning: Signs. Legas Publishing.

Merrell, F. (2003). Sensing corporeally: Toward a posthuman understanding. Toronto: University of Toronto Press.

Moran, R. (1994). The expression of feeling in imagination. The Philosophical Review, 103(1), 75-106.

Nichols, S. (Ed.). (2006). The architecture of the imagination: New essays on pretence, possibility, and fiction. Oxford: Clarendon.

Nussbaum, M. C. (1990). Love's knowledge. Oxford: Oxford University Press.

Nussbaum, M. C. (2001). Upheavals of thought: The intelligence of emotions. Cambridge: Cambridge University Press.

Oatley, K. (1994). A taxonomy of the emotions of literary response and a theory of identification in fictional narrative. Poetics, 23, 53-74.

Oatley, K. (1999). Why fiction may be twice as true as fact: fiction as cognitive and emotional simulation. Review of General Psychology, 3(2), 101-117.

Rosaldo, M. (1980). Knowledge and passion. Cambridge: Cambridge University Press.

Solomon, R. C. (1984). The passions: The myth and nature of human emotions. New York: Doubleday.

Solomon, R. C. (Ed.). (2004). Thinking about feelings. Oxford: Oxford University Press.

Stecker, R. (1984). Expression of emotion in (some of) the arts. Journal of Aesthetics and Art Criticism, 42(4), 409-418.

Valsiner, J. (2000). Culture and human development. London: Sage.

Valsiner, J. (2007). Culture in mind and societies: Foundations of cultural psychology. London: Sage.

Valsiner, J., \& Rosa, A. (Eds.). (2007). The Cambridge handbook of sociocultural psychology. Cambridge: Cambridge University Press.

Valsiner, J., \& van der Veer, R. (2000). The social mind: Construction of the idea. Cambridge: Cambridge University Press.

Vandenbos, G. R. (2007). APA dictionary of psychology. American Psychological Association.

Walton, K. (1990). Mimesis as make-believe: On the foundations of the representational arts. Cambridge: Harvard University Press. 
Walton, K. (2006). On the (so-called) puzzle of imaginative resistance. In S. Nichols (Ed.), The architecture of the imagination: New essays on pretence, possibility, and fiction (pp. 137-147). Oxford: Clarendon.

Weinberg, J. M., \& Meskin, A. (2006). Puzzling over the imagination: Philosophical problems, architectural solutions. In S. Nichols (Ed.), The architecture of the imagination: New essays on pretence, possibility, and fiction (pp. 175-202). Oxford: Clarendon.

Maria Virginia Machado Dazzani, Ph.D is Professor at Universidade Federal da Bahia, Brazil, and Researcher of Coordenação de Aperfeiçoamento de Pessoal de Nivel Superior (CAPES). She has been working with Psychology, Education and Semiotics. She is author of Rorty \& the Education (2010) and Educational Evaluation (2009).

Waldomiro José Silva Filho, Ph.D is Associated Professor at Universidade Federal da Bahia, Brazil, and Researcher of Conselho Nacional de Pesquisa Científica (CNPq) and Coordenação de Aperfeiçoamento de Pessoal de Nivel Superior (CAPES). He has been working with Philosophy of Mind and Epistemology, carrying out research on self-knowledge, anti-individualism and rationality. He is author of Mind, Language, and World (2010), Davidson and Philosophy (2008), Meaning, Interpretation, and Truth (2005). 